\title{
NEW INDUSTRY STANDARDS TO INCREASE THE RELIABILITY OF DRILLING OPERATIONS
}

\author{
D.S. AMORIM JR. ${ }^{1}$, O.L.A. SANTOS ${ }^{2}$, R.C. AZEVEDO ${ }^{3}$ \\ Universidade de São Paulo \\ dalmo.amorim@gmail.com ${ }^{1}$
}

Artigo submetido em 18/09/2019 e aceito em 20/11/2019

DOI: $10.15628 /$ holos.2019.9009

\section{ABSTRACT}

Design engineers select drilling bits based on their professional experience and knowledge about the area of the upcoming wells. Due to the absence of widely accepted algorithms for this task, diverse performance projections can come out if prepared by different persons. By selecting bits to withstand ranges of parameters similar to the used in offset wells, less failures and longer runs can be expected. In deeper wells, a slow increase in the modes of string harmonics makes well planning complex, becoming crucial for the endurance of drilling bits to avoid resonance. Two new standards are proposed to the Oil \& Gas industry in this article, created to make well planning more effective and to increase safety in selecting drilling parameters at the rig. An environment of higher drilling efficiency will result in more reliable operations and lower operational costs.

Keywords: Triangle of Normal Wear, Drilling dynamics, Reliability.

\section{RESUMO}

Engenheiros de projetos selecionam brocas para poços vindouros baseados em sua experiência profissional e o conhecimento da área. Devido à ausência de algoritmos de aceitação geral para essa tarefa, diferentes profissionais terminarão por produzir projetos diferentes. Ao selecionar brocas adequadas para suportar parâmetros similares aos utilizados nos poços de correlação, trechos mais longos e menos falhas podem ser esperados. À medida que os poços se aprofundam há um lento incremento no número de harmônicos de vibração da coluna de perfuração, o que torna projetos de poço ainda mais complexos, sendo crucial para a sobrevivência das brocas evitar a ressonância. Nesse artigo dois novos padrões são propostos para a indústria de petróleo, criados para tornar um projeto de poço mais efetivo, bem como aumentar na sonda a segurança na seleção de parâmetros adequados. Um sistema de perfuração mais eficiente deverá produzir operações mais seguras, confiáveis e de menor custo operacional. 


\section{INTRODUCTION: PLANNING DRILLING OPERATIONS}

\subsection{Purpose}

Design engineers are supported in the planning process by the style sheets of the drilling bits, containing information as the type of connection, dimensions, patented technologies, shape of cutters or inserts, types of nozzles etc. (King, 2003). To comply with the recommendations made by manufacturers, a table of parameters is supplied, like shown in Fig. 1.

$\begin{array}{ll}\text { Recommended Operating } \\ \text { Parameters } \\ \text { Weight on Bit Range } \\ \text { Max (klbs) } \\ \text { Min (klbs) } & 45 \\ \text { Max (tonne) } & 15 \\ \text { Min (tonne) } & 20 \\ \text { Rotary Speed (RPM) } & 7 \\ \end{array}$

Figure 1 - Actual drilling parameters for an 8.1/2" IADC 537 insert bit. Source:

National Oilwell Varco.

While drilling, the level of mechanical energy provided to the system is controlled by the driller, respecting the limits of recommended weight on bit (WOB) and rotary speed (RPM). A common interpretation for this style sheet, graphically expressed by the rectangle of Fig. 2, is that rotational speed ranges from 200 to $60 \mathrm{rpm}$ and weight on bit ranges from 15,000 to 45,000 lb.

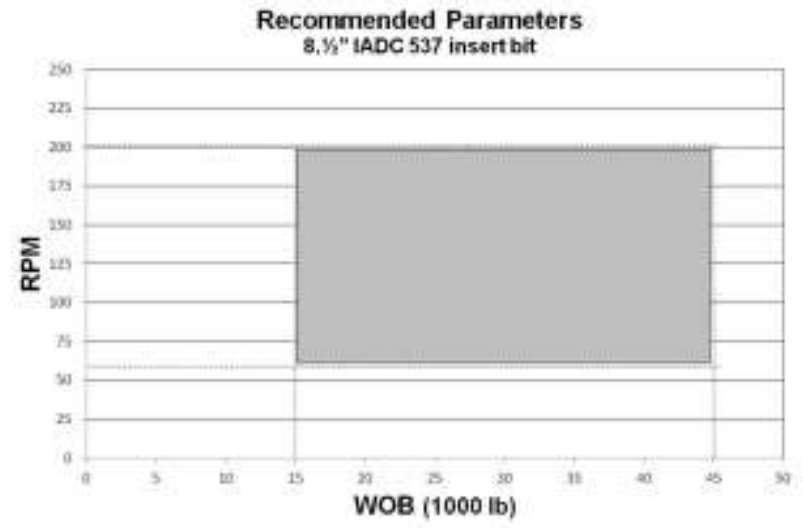

Figure 2 - Common interpretation of recommended parameters. Source: the authors.

This article discusses harmful consequences that arise from the way the information is presented. Based on extensive experience of the authors, two new standards are proposed: a simple concept to help well planning and support monitoring parameters at the rig, and a change in style sheets of drilling bits to assure drilling happens within the technical limits recommended by manufacturers. 


\subsection{Selection of rollercone bits}

The time necessary to drill a section is estimated by analyzing existing performances from offset wells. Since time estimations are based on professional experience, different results can be expected from different project engineers. In the 90's, to support design engineers in well planning, the IADC (International Association of Drilling Contractors) created a standard for the selection of rollercone bits (McGehee, D.Y. et al., 1992), seen in Fig. 3, associating a bit type with characteristics of usage. Despite needing an update, this codification has been largely used since then.

\section{A. D. C. ROLLER BIT CLASSIFICATION CHART}

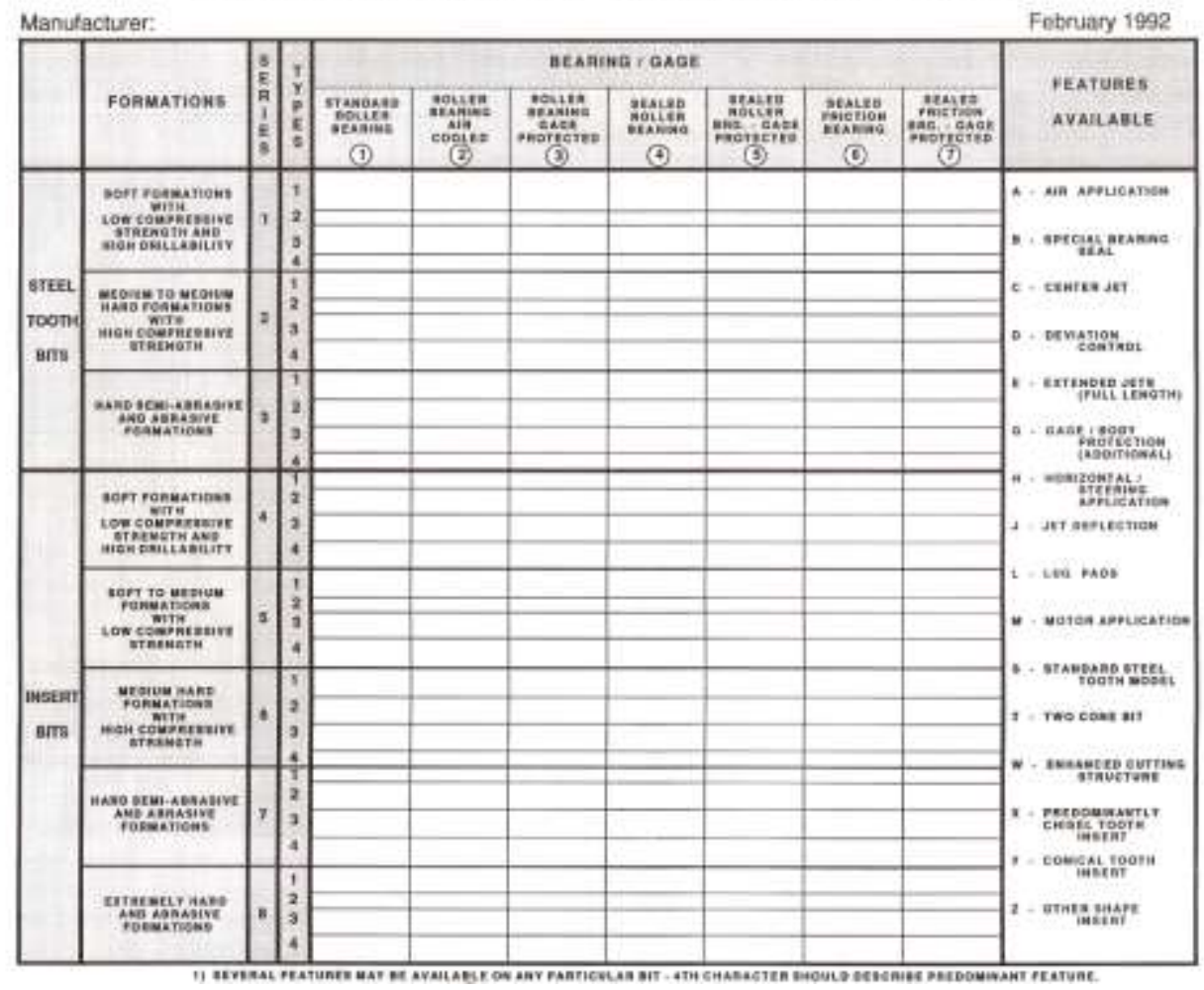

Figure 3 - IADC Rollercone Bit Classification, 1992.

The selection of the technology of a bit is based at the expected loads necessary to crush the rock, abrasiveness of the formation, trajectory, usage of a downhole motor, available hydraulics etc (Simmons, 1986). The life of the cutting structure can be extended with less protrusion to mitigate insert breakage, and the rate of penetration (ROP) can be increased by using inserts or teeth. A balance between ROP and life of the bit will determine the cost per meter of the operation.

Improvements are also devised to extend the life and reliability of bearings by using thicker walls of steel cones, premium elastomers in seals and pressure compensation systems, tougher mandrels, temperature resistant grease, ultra-polished rotating friction surfaces, diamond protection in the gage area, coated steel teeth and impact resistant inserts (Chen, 2000). Such features define the design of cones, lugs, mandrels and other elements of the cutting structure. 
Bit prices are determined by their technologies and features. Although resulting in a higher acquisition price, premium features significantly reduce costs producing longer runs and higher reliability to the operation, avoiding reaming out-of-gage wells and by reducing risks of failure.

After the end of a bit run, the drill string is pulled from the well. Bit wear is classified using the 8-digit standard proposed by IADC (McGehee, et al., 1992), seen in Fig. 4. The information is registered in the Bit Record together with the performance, parameters, inclination, pull date etc. This procedure plays an important role in the planning of future wells, as offset data has remarkable valuable in supporting the selection of bits and parameters in the same region.

\begin{tabular}{|c|c|c|c|c|c|c|c|}
\hline \multicolumn{4}{|c|}{ Cutting Structure } & B & G & \multicolumn{2}{|c|}{ Remarks } \\
\hline Inner & Outer & Dull & Loca & Brng & Gage & Other & Reason \\
\hline $\begin{array}{l}\text { Rows } \\
\text { (I) }\end{array}$ & $\begin{array}{c}\text { Rows } \\
(\mathrm{O})\end{array}$ & $\begin{array}{l}\text { Char. } \\
\text { (D) }\end{array}$ & $\begin{array}{l}\text { tion } \\
\text { (L) }\end{array}$ & $\begin{array}{r}\text { Seal } \\
\text { (B) }\end{array}$ & $\begin{array}{r}1 / 16 \\
(G)\end{array}$ & $\begin{array}{l}\text { Dull } \\
\text { (O) }\end{array}$ & $\begin{array}{l}\text { Pulled } \\
\text { (R) }\end{array}$ \\
\hline
\end{tabular}

Figure 4 - The IADC Roller Bit Dull Grading System.

\subsection{Selection of fixed cutter bits}

IADC proposed a similar standard for fixed cutter bits, reflecting existing technology in the 90's (Brandon, B.D. et al., 1992). The standard is out of date, needing a complete review to comply with the great evolution experienced by PDC bits last decades (Scott, 2005). The dull grading system is similar to the one used for rollercone bits, disregarded the information of the bearing seals (B).

The life of a fixed cutter bit can be extended with higher density of cutting elements, premium or smaller cutters, extra gauge protection and torque control elements (Barton, S. et al., 2008).

\subsection{Drilling operations}

A drilling operation relies on the usage of mechanical energy to advance the well trajectory. To drill, part of the mass of the suspended string is relieved, applying weight on the bit. Meanwhile torque is applied to rotate the bit, the rock is crushed and cutters move ahead. Turbines and Positive Displacement Motors (PDM) can be used right above the bit, providing additional rotational speed by using hydraulic energy to turn the shaft (Clegg, J., 2019).

The rate of penetration is directly related to the levels of energy that reach the cutting structure of the bit, the hydraulics that remove cuttings, and the hydrostatic produced by the drilling fluid, preventing that cuttings are detached from the formation (Teodorescu, 2016).

The weight applied at a rotating bit alters the stress status of every element of the drill string. This causes some combinations of WOB $\times$ RPM to produce vibrations, resulting in the dissipation of energy, reducing the efficiency of the drilling process (Javanmardi \& Gaspard, 1992). If $100 \%$ of efficiency were achieved while drilling, the Mechanical Specific Energy (psi) or MSE (Teale, 1965) would be equal to the formation hardness (psi). Drill string dynamics alter as new joints of pipe are added, with a progressive increase in resonance modes that reduce the efficiency of the drilling operation (Amorim Jr., et al., 2012). 


\subsection{Major elements that affect a drilling operation}

A drilling bit will be at the end of a complex environment that includes: (a) rig systems, (b) a drill string composed by drill pipes, drill collars, downhole tools and the bit; (c) the trajectory of the well and tortuosity; (d) fluids; (e) the lithology of geological formations. This conjunction of facts produces a progressively harmful environment as the well is drilled, contributing to inefficiency and demanding constant adjustments in the energy levels provided.

- Progressive increment of friction is the result of adding joints of pipe, demanding increasing torque from the rotating system, especially in directional wells;

- Tortuosity is an obstacle for even distribution of torque throughout the drill string, becoming difficult to have a constant value of WOB applied in tortuous trajectories;

- Decreases in the rate of penetration are due to drill harder rock, to the loss of sharpness of the cutting structure and to the loss of efficiency, progressively demanding solutions as changing to another bit type or progressively applying more weight.

\subsection{Extending bit life}

Ideally, a bit should drill cement and casing shoe to the total depth of the section, being pulled in reusable or repairable condition, without losing gage diameter to avoid reaming operations. The achievement of low operational costs is the result of using a proper bit to drill faster and longer, pulled only when evidences show the need to replace it (Garner, 1982).

Abrasion and erosion continuously wear out the cutting structure, so even wearing is desirable to balance cutting forces and achieve long runs. To withstand the high loads typically encountered when drilling hard and abrasive rocks, tougher, better-protected and more expensive drilling bits are needed.

As wells gets deeper, bit endurance and reliability, rather than ROP, become a major objective in cost reduction. Reliability is a useful industry standard of statistical analysis to simulate bearing life, serving as an additional flag in defining the best moment for the replacement of the bit. Based on operational data from offset wells, curves of Bit Rotating Hours $\mathrm{x} \%$ Reliability are built to estimate $80 \%$ of a bearing life. The results are expressions of stress, measured in hours $(h)$, thousands of bit revolutions (kRev, dimensionless) or billion-pound revolutions (BPR, kRev $x$ WOB, lb) (KissSoft, 2013). Some variables are not considered in conventional standards of reliability, like type of grease, downhole temperatures or the quality of the finishing of rotating surfaces (Huang \& Li, 2018). Despite more reliable for not using bearings (Bruton, et al., 2014), there is not an algorithm to calculate the reliability of the cutting structure of fixed cutter bits.

\subsection{Friction}

The trajectory is continuously built as new pipe is added, producing gradual changes in the suspended weight and an increased contact area with the walls. The friction of string elements in contact with the walls, when rotating or sliding, absorbs part of the energy input in the system. In directional wells, friction might absorb the loaded weight, holding the bit off the bottom. When friction is overcome, the string slides and significant loads might damage the cutting structure of the bit, cutting elements of the hole opener, and mechanical or electronic elements of downhole tools. 
The magnitude of friction can be predicted by FEA pre-analysis (Goicoechea, H. E. et al., 2019), being primarily reduced by using lubricants in the drilling fluids, stabilizers or roller reamers to keep the bottom hole assembly centralized, and downhole motors or turbines to promote higher speed of rotation directly at the bit (Fazaelizadeh, 2013), reducing string RPM.

\subsection{Vibrations}

Drilling vibrations can produce dramatic reductions in the efficiency of a drilling operation by dissipating a substantial fraction of the energy, quickly reflected in a ROP drop. Eventual reductions in performance raise concerns to the driller about needing to adjust the pre-planned parameters or switch to a bit type better adjusted to the environment (Lee, S.S. et al., 2018).

Increasing drilling parameters is not itself a guarantee of achieving higher ROP. Should a driller have the choice to combine parameters to be within the zone of Stable Drilling, seen in Fig. 5, drilling would occur with higher efficiency. Some combinations of WOB $\times$ RPM (Christian, 2017) can result in complex and detrimental effects to drilling performance, like bit whirl, stick slip, bit bounce, linear coupling, parametric coupling between axial and bending vibrations (Jogi, P.N. et al, 2002), and chaotic whirl (Christoforou \& Yigit, 1997).

The most harmful drilling mode is the chaotic whirl, a destructive form of vibration aggravated by the excessive energy input in a drilling system under resonance. In such mode, the bit and/or the string rotate precessionally about the center of the wellbore axis, alternating with clockwise and counterclockwise rotation (Rodney, 2015). At the bottom of the string, cyclic peaks of RPM values much higher than supplied by the top drive or rotary table, cause premature wear of stabilizer blades, bit gauge protection and bearings, leading to accidents and fishing jobs.

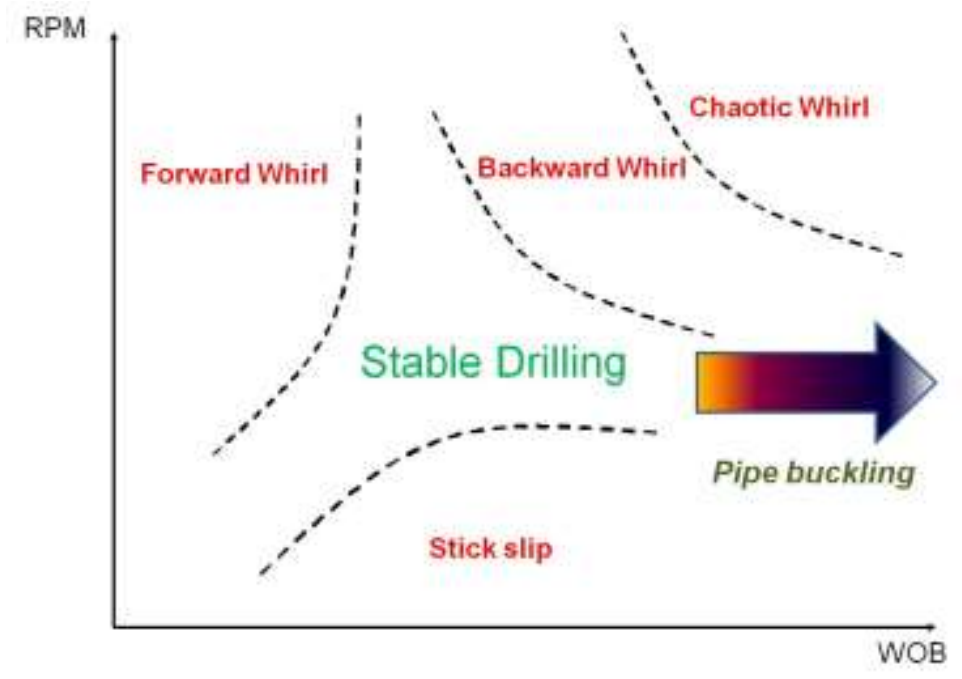

Figure 5 - WOB x RPM drilling modes. Source: the authors. 


\section{MATERIALS AND METHODS: IMPROVING THE EFFICIENCY OF THE DRILLING OPERATIONS}

\subsection{Detecting drilling vibrations}

The response to stress is strongly dependent on the stiffness of the system (Greenhill \& Cornejo, 1995). High stress levels reflect negatively on drilling costs because of the need to use thicker drill pipe, to upgrade the electric motor of the top drive and to purchase expensive bits to resist longer to impacts, surviving to an excessive exposure to abrasion. Connections might also become strongly tightened, demanding additional trip time to be unscrewed. Vibration detection and constant survey of the energy applied must be part of any methodology aiming to reduce drilling costs.

Torsional vibrations - affect rig components like the top drive or rotary table, being noticeable in the rig floor by the cyclic variations of the sound from their motors and by torque sensors. The phenomenon known as stick-slip is produced by elements of the drill string contacting the walls while rotating, with torque being absorbed by friction and redistributed throughout the elastic string, aggravated by narrow contacts, like the underreamers (Moraes \& Savi, 2018) and the bit cutters. Sequential short heat \& cool cycles cause a quick deterioration of abrasion resistant elements at the gauge of bit and stabilizer blades.

Axial vibrations - produce remarkable signs at the rig floor, like swinging drilling cables and shaking the rig derrick, they are noticed in a sensor due to cyclic variations in the suspended weight.

Lateral vibrations - dynamic loads and impacts at the bottom are not detected by conventional rig sensors at the surface, though causing whirling at the bottom hole assembly (BHA) and drilling bit (Ghasemloonia, A., 2012). Such detrimental effects result in abnormal bit wear and premature failure of drilling tools. Measure While Drilling tools (MWD) can detect their effects close to the bit in real time, like lateral impacts in electronic tools and those produced by slide steering in complex trajectories (Peng et al., 2018).

\subsection{Mitigating drilling vibrations}

Vast literature and patents are available on how to mitigate vibrations in the drilling environment (Hutchinson, 2006). Some practices have been used by decades, like replacing stabilizers by roller reamers to mitigate torsional vibrations, and shock tools to mitigate axial vibrations.

Last decade the major bit manufacturers lead the development of proprietary FEA software to predict the harmonics of a drill string under stress and rotation. The action was initiated as sales tools to improve the performance of their drilling bits; however, such practices are not yet of current use due to being unknown, to be understood as an action of marketing or not seen as a valid investment to increase the reliability of bits and downhole tools.

\subsection{FEA pre-analysis to support the selection of parameters}


FEA pre-analyzes represent a valuable tool in parameter planning by predicting the harmonics of a drill string versus the measured depth of the well. They take in account the material, weight and stiffness (length and cross-sectional area) of all elements of the drill string (pipe, collars and tools). The simulation is made considering the actual trajectory, for the true vertical depth, diameter of the borehole, state of pressure around the drill string (hydrostatic produced by the drilling fluid) and the frequency of excitation of the system, e.g. the rotational speed of the drill string.

A typical FEA output chart is seen in Fig. 6. A noticeable progressive change in harmonics happens as pipe joints are added, becoming the string progressively more flexible. In deep sections, rigid drill collars no more respond for the high stiffness of the string in shallower depths.

When FEA is combined with a MWD tool, both will support the rig crew in validating the planned parameters, also producing an additional flag regarding the best moment to pull the bit.

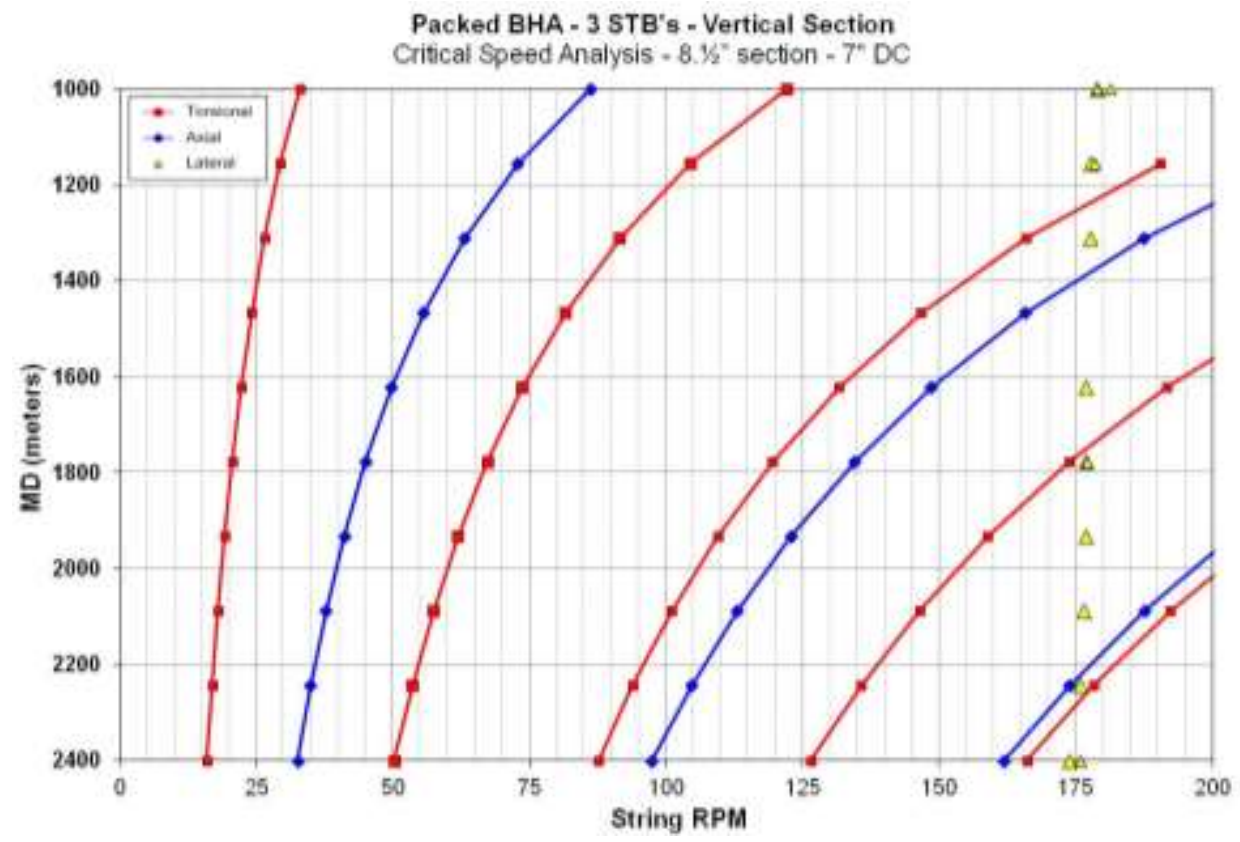

Figure 6 - FEA prognosis of torsional, axial and lateral harmonic peaks $x$ depth (Amorim Jr., et al., 2012).

\section{RESULTS - NEW STANDARDS IN DRILLING OPERATIONS}

To comply with the ideas discussed, the authors propose two new standards: SME, or the Simple Mechanical Energy factor, and the Triangle of Normal Wear.

\subsection{Simple Mechanical Energy - SME}

$$
\begin{gathered}
\boldsymbol{S M E}=W O B \times R P M(\mathrm{lbf} / \mathrm{min}) \\
\text { Equation } 1 \text { - Simple Mechanical Energy (SME) }
\end{gathered}
$$

Analog to MSE (Berg \& Tveit, 2016), SME is a measure of the mechanical energy used in a drilling operation, created to improve the pre-planning of parameters, complying with values of $S M E_{\min }$ and $S M E_{\max }$ for each model and size of drilling bit, defined by manufacturers. 
- $\mathrm{SME}_{\min }$ - minimum SME level, represented by the vertex of the triangle in Fig. 7

- $\mathrm{SME}_{\max }$ - maximum SME level, represented by the dotted line in Fig. 7

By knowing the necessary mechanical energy used in offset wells, a Project Engineer will be able to select a bit that withstands the expected SME. If not able, other bit projected to stand a higher $\mathbf{S M E}_{\max }$ should be selected.

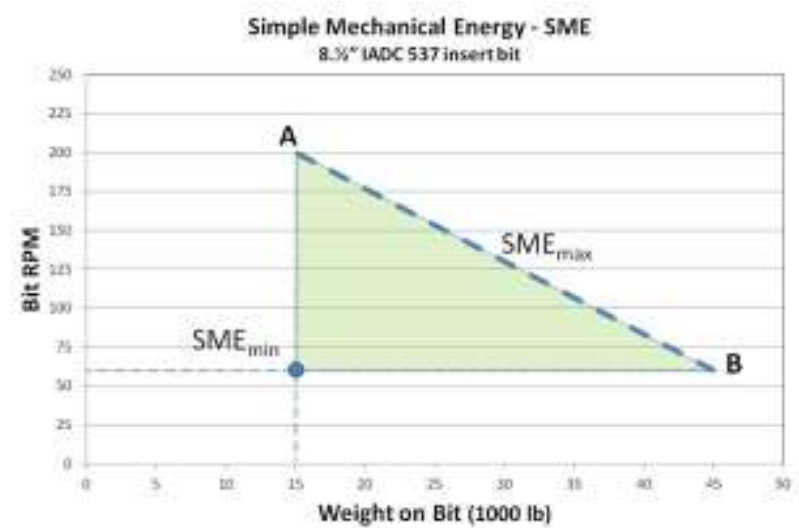

Figure 7 - Recommended SME for an 8.1\%2" IADC 537 insert bit. Source: the authors.

A correspondent chart should be part of the style sheet of drilling bits, working as an aid for rig personnel to make sure drilling relies within $S M E_{\min } \leq S M E \leq S M E_{\text {max }}$.

\subsection{Triangle of Normal Wear}

Any combination of WOB $x$ RPM in a drilling operation will be represented by one of the eight areas of Fig. 8. Benefits, menaces and performances are exposed in Table 1.

\begin{tabular}{|c|c|c|}
\hline Area & Name & Benefits and menaces of different WOB $\times$ RPM combinations \\
\hline 1 & $\begin{array}{l}\text { Triangle of } \\
\text { Nomal Wear }\end{array}$ & Highest reliability, longer rums, fewer trips, lowest costs: reduced risks. \\
\hline 2 & $\begin{array}{l}\text { Triangle of } \\
\text { Accelerated Wear }\end{array}$ & $\begin{array}{l}\text { Applicable in short lengths of hard-interbedded formations for higher instant } \\
\text { ROP, compromising reliability; potential occurrence of destructive whirling. }\end{array}$ \\
\hline 3 & $\begin{array}{l}\text { Insufficient } \\
\text { parameters }\end{array}$ & $\begin{array}{l}\text { Low productivity, high cost per meter. Caused by short time distractions of } \\
\text { drillers giving orders or taking notes. Replace the driller by an assistant or use } \\
\text { the automatic driller to keep SME inside the Triangle of Nomal Wear. }\end{array}$ \\
\hline 4 & Insufficient WOB & $\begin{array}{l}\text { Low productivity, high cost per meter. Beneficial when bringing a trajectory to } \\
\text { vertical; forward whirling and axial vibrations can be expected. }\end{array}$ \\
\hline 5 & Insufficient RPM & $\begin{array}{l}\text { Low productivity, high cost per meter. Beneficial when cutting cement inside } \\
\text { the casing to avoid torque peaks that can result in unscrewed casing segments. }\end{array}$ \\
\hline 6 & Excessive RPM & $\begin{array}{l}\text { Shorter bit life, risks of failure of rollercone bits. Environment of destructive } \\
\text { backward whirling if high WOB is used; chipped or broken inserts. }\end{array}$ \\
\hline 7 & Excessive WOB & $\begin{array}{l}\text { Shotter bit life, risks of falure of fixed cutter bits. Environment of destructive } \\
\text { backward whirting if high RPM is used, quickly destroying the bit. }\end{array}$ \\
\hline 8 & $\begin{array}{l}\text { Excessive } \\
\text { parameters }\end{array}$ & $\begin{array}{l}\text { Chaotic whirl, short bit runs, tool failures and quick destruction of elements of } \\
\text { the drill string. Lost cones, broken blades, twist off or unscrewed pipe. }\end{array}$ \\
\hline
\end{tabular}

Table 1 - WOB x RPM combinations in a drilling operation. 
The parameters recommended by the bit manufacturers are represented by the Triangle of Normal Wear, seen in area 1 of Fig. 8. Any combination of WOB $\times$ RPM inside that area implies that drilling will occur within $S M E_{\min } \leq S M E \leq S M E_{\text {max }}$, providing that the highest reliability and the lowest operational costs will be achieved.

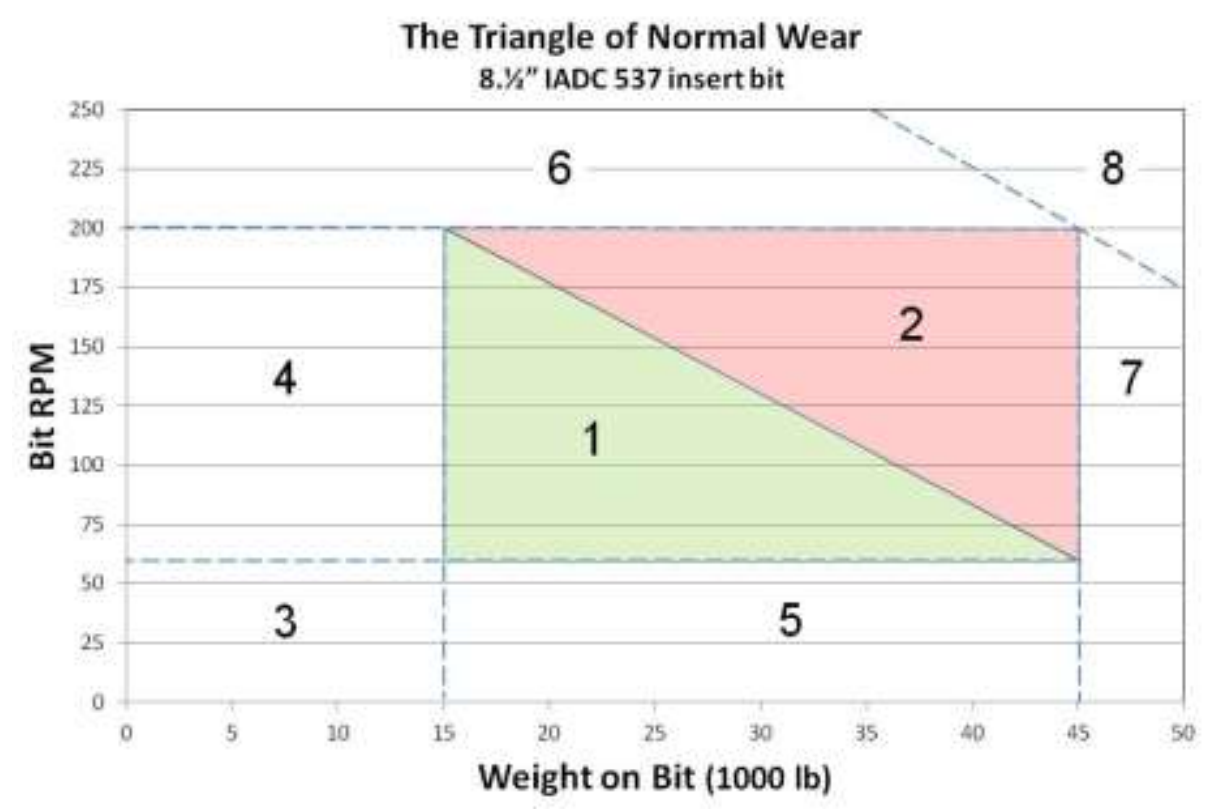

Figure 8 - Area 1 represents the recommended drilling parameters. Source: the authors.

\section{DISCUSSION}

\subsection{Interpretation of FEA pre-analysis for parameter selection}

A FEA pre-analysis chart is very useful in the process of well planning. By gradually selecting a depth and choosing a RPM value within two curves, drilling is done out of resonance. The selected RPM must comply with limitations of the rig and recommendations from the bit manufacturers. By avoiding vibrations, a higher ROP and an optimized time to drill a section are expected.

Lesson learned - soft rock: in Fig. 9, 130 RPM is an environment of high efficiency at $1200 \mathrm{~m}$, expected to produce a ROP higher than if using 175 RPM, where lateral resonance affects drilling despite a higher SME. The absence of a FEA analysis has lead to common equivocated conclusions about causes of higher ROP. Examples: to be drilling a softer formation or to be using a bit of a determined better brand, situations possibly produced by a momentary efficient environment. 


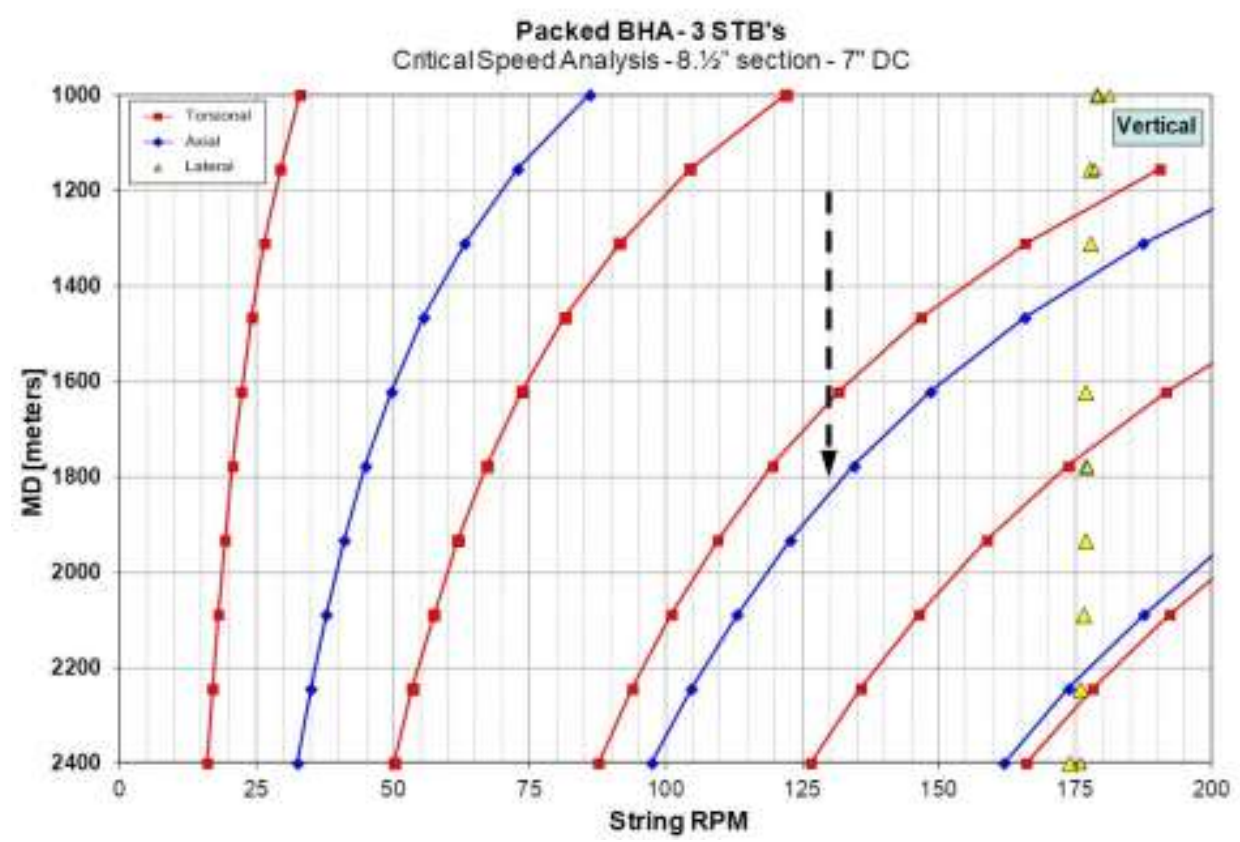

Fig. 9 - Effect of vibrations on drilling operations without changing parameters.

Lesson Learned - hard rock: drilling from 1200 to $1800 \mathrm{~m}$, with same 130 RPM, will result in a ROP reduction due to progressive combined torsional and axial vibrations. The absence of a FEA analysis has lead to conclusions like to be drilling hard rock, or that the cutting structure is worn out, leading to unnecessary trips to replace the bit. Efficient combinations of WOB $x$ RPM, for a certain depth, are the environment of a disaster in other depths of the same section.

Lesson learned - deep wells: four peaks of resonance exist at the depth of $1000 \mathrm{~m}$, being one axial, one lateral and two torsional modes. At $2400 \mathrm{~m}$, nine peaks exist, caused by progressive flexibility of the string by addition new of pipe joints, explaining an empirical finding about how difficult it is to determine steady parameters in deep wells. This is also true in deep wells, where fishing jobs are more common than in shallower depths. Multiple modes of resonance combined with high levels of energy are very harmful to the integrity of bits and tools.

Low ROP can be the result of low efficiency caused by vibrations, many time attributed to hard rock, wrong bit selection or to a dull cutting structure. Despite its low performance, some trips have ended pulling bits in relatively good shape, in truth caused by drilling under resonance.

4.2. Using SME to increase the reliability of drilling operations

Calculating $\mathrm{SME}_{\max }$ for the style sheet of Fig. 1:

- $\quad$ Point $A$ in Fig. 7: SME $=\operatorname{SME}(200,15000)=200 \times 15000=3,000,000$

- $\quad$ Point $B$ in Fig. 7: SME $=\operatorname{SME}(60,45000)=60 \times 45000=2,700,000$

$$
\mathrm{SME}_{\max }=3,000,000
$$

Calculating $\mathrm{SME}_{\max }$ for the combination of maximum parameters shown in Fig. 2:

$$
\operatorname{SME}(200,45000)=9,000,000=3.3 \times \operatorname{SME}_{\max }
$$

This demonstrates the authors' vision about the equivocated way such information is provided in the style sheets, as the bit might receive loads to which it has not been projected. 


\subsection{Benefits of the proposed standards}

- Plan bit type according to the expected $\mathbf{S M E}_{\max }$

- Limit WOB $\times$ RPM to the parameters recommended by the bit manufacturer

- Increase the reliability of the operations

- Reduce risks of damaging bits upon repair

- Reduce drilling costs

\section{CONCLUSIONS}

\subsection{IADC standards}

The petroleum industry has not produced an update of the IADC standards for Bit Classification since the 90's. Well planning has become passive of subjective interpretations due to be based on some obsolete technologies, materials and concepts, especially for fixed cutter bits.

An update for rollercone bits should include the number of inserts versus bit diameter, helping to make realistic comparisons of bits that work with similar values of $\mathbf{S M E}_{\max }$.

An update for fixed cutters should review concepts in bit design, size of cutters, body materials, number and shape of blades, including codes for hydraulic design, torque control components and features that improve the stability of the bit, also including the concepts contained in this article.

An update for the 8-digit standard for bit wear should include a CM code, reporting the bit was pulled due to an increase in the cost per meter. This is a relevant cause to determine the end of a run, but never surveyed due to the absence of the code.

\subsection{New standards for well and parameter planning}

The way the recommended parameters are presented in style sheets can produce interpretations detrimental to the reliability of drilling operations. SME was conceived to support well planning and to be a conventional drilling practice, coping with specifications made by the bit manufacturers.

The Triangle of Normal Wear, conceived to support bit selection and produce longer runs, should improve even wear of the elements of the cutting structure.

Combined with FEA vibration pre-analysis, both practices should result in higher reliability and a decrease in operational costs, achieved by longer runs and fewer trips to check bit conditions, also minimizing reaming operations to repair undergauged wells and fishing jobs.

Plotting WOB $x$ RPM of a bit run in a chart similar to Fig. 7 can provide helpful tools in supporting reports and investigations of drilling accidents.

\subsection{Combining physical models}

The conjunction of concepts from the Triangle of Normal Wear and concepts of the science of vibrations results in the model proposed in Fig. 10. 


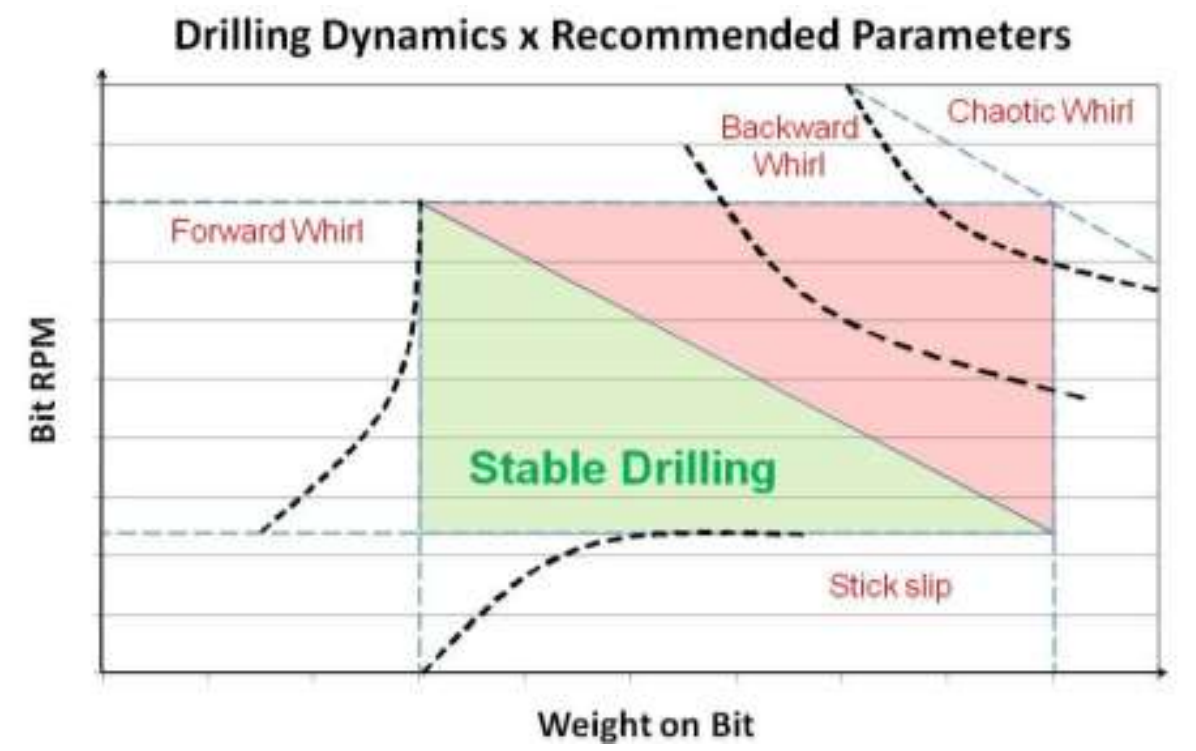

Figure 10 - Proposed model for drilling environments. Source: the authors.

\section{REFERENCES}

Amorim Jr., D. S., Hanley, C., Fonseca, I., Santos, J., Leite, D. J., Borella, A., et al. (2012). Parameter Definition Using Vibration Prediction Software Leads to Significant Drilling Performance Improvements. In G. a.-I. Brazilian Petroleum (Ed.), Rio Oil \& Gas Expo and Conference, (p. 17). Rio de Janeiro, Brazil.

Barton, S. et al. (2008). Controlling Torque and Cutting Costs: Steerable Drill Bits Deliver in Latin America. In G. a.-I. Brazilian Petroleum (Ed.), Rio Oil \& Gas Expo and Conference 2008 (p. 8). Rio de Janeiro: IBP.

Berg, P. V., \& Tveit, $\varnothing$. S. (2016). Model for evaluating drilling efficiency based on the concept of Mechanical Specific Energy. Norwegian University of Science and Technology, Department of Petroleum Engineering and Applied Geophysics. Trondheim, Norway: NTNU.

Brandon, B.D. et al. (1992). Development of a New IADC Fixed Cutter Drill Bit Classification System. In IADC/SPE (Ed.), 1992 IADC/SPE Drilling Conference, IADC/SPE 23940, pp. 841-848. New Orleans, USA.

Bruton, G., Crockett, R., Taylor, M., DenBoer, D., Fleming, C., Ford, R., et al. (2014). PDC Bit Technology for the 21st Century. Oifield Review , 26 - 2, 48-57.

Chen, S. (2000). Patent No. US6095262A. USA.

Christian, E. (2017). Identifying the Optimum Zone for Reducing Drill String Vibrations. SPE Annual Technical Conference and Exhibition, 9-11 October, (p. 12). San Antonio, Texas, USA: Society of Petroleum Engineers.

Christoforou, A. P., \& Yigit, A. S. (1997). Dynamic Modelling of Rotating Drillstrings with Borehole Interactions. (A. P. Limited, Ed.) Journal of Sound and Vibration , 243-260. 
Clegg, J., Mejía, C., \& Farley, S. (2019). A Paradigm in Rotary Steerable Drilling - Market Demands Drive a New Solution. SPE/IADC International Drilling Conference and Exhibition (p. 16). The Hague, The Netherlands: Society of Petroleum Engineers.

Fazaelizadeh, M. (2013). Real Time Torque and Drag Analysis during Directional Drilling (Thesis for Doctoral Degree ed.). (D. o. Engineering, Ed.) Calgary, Alberta, Canada: Faculty of Graduate Studies.

Garner, L. L. (1982). Patent No. 4359335A. USA.

Ghasemloonia, A. (2012). Vibration Analysis of a Drillstring in Vibration-Assisted Rotary Drilling: Finite Element Modeling With Analytical Validation. Journal of Energy Resources Technology, 135, 18.

Goicoechea, H. E., Buezas, F. S., \& Rosales, M. B. (2019). A non-linear Cosserat rod model for drillstring dynamics in arbitrary borehole geometries with contact and friction. International Journal of Mechanical Sciences, Volumes 157-158, 98-110.

Greenhill, L., \& Cornejo, G. (1995). Critical Speeds Resulting from Unbalance Excitation of Backward Whirl Modes. Design Engineering Technical Conferences (pp. 991 - 1000). Boston, MA - USA: ASME.

Huang, Z. Q., \& Li, G. (2018). Failure Analysis of Roller Cone Bit Bearing Based on Mechanics and Microstructure. Journal of Failure , 18, 342-349.

Hutchinson, M. (2006). Patent No. US7140452 B2. United States.

Javanmardi, K., \& Gaspard, D. T. (1992). Application of Soft-Torque Rotary Table in Mobile Bay. SPE/IADC Drilling Conference (p. 6). Louisiana: Society of Petroleum Engineers.

Jogi, P.N. et al. (2002). Field Verification of Model-Derived Natural Frequencies of a Drill String. Hostoun, USA: Amercian Society of Mechanical Engineers - ASME.

King, W. (2003). Patent No. US6612382B2. UK.

KissSoft. (2013, 03). Kadkraft Systems. Retrieved 06 06, 2018, from KISSsoft: http://kadkraft.com/wp-content/uploads/2015/06/THE-KSO-AS-1750-00-EES-BearingReliability.pdf

Lee, S.S. et al. (2018). Development of a trip time for bit exchange simulator for drilling time. Geothermics, 71, 24-33.

McGehee, D. Y., Dahlem, J. S., Gieck, J. C., Kost, B., Lafuze, D., Reinsvold, C. H., et al. (1992). The IADC Roller Bit Dull Grading System. IADC/SPE Drilling Conference (pp. 819-834). Louisiana, USA: IADC/SPE.

McGehee, D.Y. et al. (1992). The IADC Roller Bit Classification System. IADC/SPE 23937 (pp. 801 818). Louisiana, USA: Society of Petroleum Engineers. 
Moraes, L. P., \& Savi, M. A. (2018, 09 07). Drill-string vibration analysis considering an axialtorsion-lateral nonsmooth model. (Elsevier, Ed.) Journal of Sound and Vibration , pp. 220-237.

Peng, W., Hongjian, N., Xueying, W., Ruihe, W., \& Shuangfang, L. (2018). Research on the characteristics of earthworm-like vibration drilling. (Elsevier, Ed.) Journal of Petroleum Science and Engineering , 160, 60-71.

Rodney, P. e. (2015). Patent No. US 20150233231A1. USA.

Scott, D. E. (2005). The History and Impact of Synthetic Diamond Cutters and Diamond Enhanced Inserts on the Oil and Gas Industry.

Simmons, E. (1986, 02 12). A Technique for Accurate Bit Programming and Drilling Performance Optimization. SPE/IADC Drilling Conference . Dallas, Texas, USA.

Teale, R. (1965, March). The Concept of Specific Energy in Rock Drilling. (I. J. Abstracts, Ed.) Isleworth, Middlesex, U.K.: Mining Research Establishment.

Teodorescu, S. G. (2016). Patent No. US9238958B2. USA, The Woodlands - TX. 